\title{
Uptake of oxytetracycline and its phytotoxicity to alfalfa (Medicago sativa L.)
}

\author{
W.D. Kong ${ }^{\text {a }}$, Y.G. Zhu ${ }^{\text {a,*, Y.C. Liang }}{ }^{\text {, }}$, J. Zhang ${ }^{\text {a }}$, F.A. Smith ${ }^{\text {c }}$, M. Yang ${ }^{\text {a }}$ \\ ${ }^{\text {a }}$ Research Center for Eco-Environmental Sciences, Chinese Academy of Sciences, Beijing 100085, China \\ ${ }^{\mathrm{b}}$ Ministry of Agriculture Key Laboratory of Plant Nutrition and Nutrient Cycling, Institute of Soils and Fertilizers, \\ Chinese Academy of Agricultural Sciences, Beijing 100081, China \\ ${ }^{c}$ Soil and Land Systems, School of Earth and Environmental Sciences, The University of Adelaide, DP 636, Adelaide, SA 5005, Australia
}

Received 28 March 2006; received in revised form 25 July 2006; accepted 2 August 2006

Plant uptake of antibiotic oxytetracycline is energy-dependent.

\begin{abstract}
A series of experiments were conducted in a hydroponic system to investigate the uptake of oxytetracycline (OTC) and its toxicity to alfalfa (Medicago sativa L.). OTC inhibited alfalfa shoot and root growth by up to $61 \%$ and $85 \%$, respectively. The kinetics of OTC uptake could be well described by Michaelis-Menten equation with $V_{\max }$ of $2.25 \mu \mathrm{mol} \mathrm{g}{ }^{-1}$ fresh weight $\mathrm{h}^{-1}$, and $K_{\mathrm{m}}$ of $0.036 \mathrm{mM}$. The uptake of OTC by alfalfa was strongly inhibited by the metabolic inhibitor, 2,4-DNP (2,4-dinitrophenol), at pH 3.5 and 6.0, but not by the aquaporin competitors, glycerol and $\mathrm{Ag}^{+}$. OTC uptake, however, was significantly inhibited by $\mathrm{Hg}^{2+}$, suggesting that the inhibition of influx was due to general cellular stress rather than the specific action of $\mathrm{Hg}^{2+}$ on aquaporins. Results from the present study suggested that OTC uptake into alfalfa is an energy-dependent process. (C) 2006 Elsevier Ltd. All rights reserved.
\end{abstract}

Keywords: Alfalfa; Medicago sativa L.; Oxytetracycline; Uptake; Veterinary pharmaceuticals

\section{Introduction}

Veterinary pharmaceuticals are widely used for the therapy of infectious diseases of animals in intensive farming systems (Halling-Sørensen and Jørgensen, 2000; Boxall et al., 2003). They are designed to act very effectively at low doses and to be completely excreted from the body after a short time of residence. It has been reported that only a fraction of the ingested antibiotics are metabolized in the animals, hence a large percentage of the antibiotics are excreted and released into the environment, e.g. via manure, sludge and waste water used as fertilizer or irrigation water into arable soils (Jørgensen and Halling-Sørensen, 2000). Therefore, residual concentrations

\footnotetext{
* Corresponding author.

E-mail address: ygzhu@rcees.ac.cn (Y.G. Zhu).
}

of pharmaceutical antibiotics can be found in soils, surface and ground water (Hamscher et al., 2002; Kolpin et al., 2002; Simon, 2005). For example, in Denmark, concentrations of oxytetracycline ranging from 2.5 to $50 \mu \mathrm{g} \mathrm{g}^{-1}$ in soil and from 33 to $2000 \mathrm{mg} \mathrm{g}^{-1}$ in pig manure have been reported (Loke et al., 2002). The fate of antibiotics, including sorption and fixation, mobility and transport in soil, has been well documented (Tolls, 2001; Kulshrestha et al., 2004; Figueroa and Mackay, 2005; Figueroa et al., 2005; Gu, 2005; Jones et al., 2005), whereas knowledge of their toxicity to plants and their uptake and transport into plants is poorly understood (Boxall et al., 2003; Thiele-Bruhn, 2003). The accumulation may or not affect the growth and development of plants; however, the uptake into plants may represent an important exposure pathway of these compounds to humans and other biota. Hence, there is a potential risk that plants might transfer antibiotics from the soil into the food chain. There are some reports dealing 
with the effects of antibiotics on plant growth and development (Batchelder, 1981, 1982; Migliore et al., 1998; Bradel et al., 2000; Jjemba, 2002a,b), but information is scant on characterizing the antibiotic uptake into higher plants.

It has been shown that bacterial uptake of tetracycline, an antibiotics similar structurally to oxytetracycline, is partially energy-dependent and hence an uptake mechanism has been proposed (Nikaido and Thanassi, 1993). According to this, tetracycline traverses the outer membrane of gram-negative bacteria through the $\mathrm{OmpF}$ and $\mathrm{OmpC}$ porins channels (Schnappinger and Hillen, 1996), chelating a $\mathbf{M}^{2+}$ ion as cation-tetracycline complexes $[\mathrm{M}-\mathrm{tc}]^{+}\left(\right.$Fig. 1). The cationic $[\mathrm{M}-\mathrm{tc}]^{+}$is attracted by the Donnan potential across the outer membrane, leading to accumulation in the periplasm, where the metal ion-tetracycline complex probably dissociates to liberate uncharged tetracycline, a weakly lipophilic molecule that is able to diffuse through the lipid bilayer regions of the inner (cytoplasmic) membrane. Similarly, the electroneutral, lipophilic form is assumed to be the species transferred across the cytoplasmic membrane of Gram-positive bacteria. Uptake of tetracycline is energy-dependent and driven by the $\Delta \mathrm{pH}$ component of the proton-motive force (Chopra and Roberts, 2001).

Although there is little information available on the mechanism of plant uptake of OTC, based on the proposal for bacteria, we hypothesize that OTC uptake by alfalfa roots is an active process that requires energy. Therefore the aim of the present study was to characterize the uptake of OTC in alfalfa.

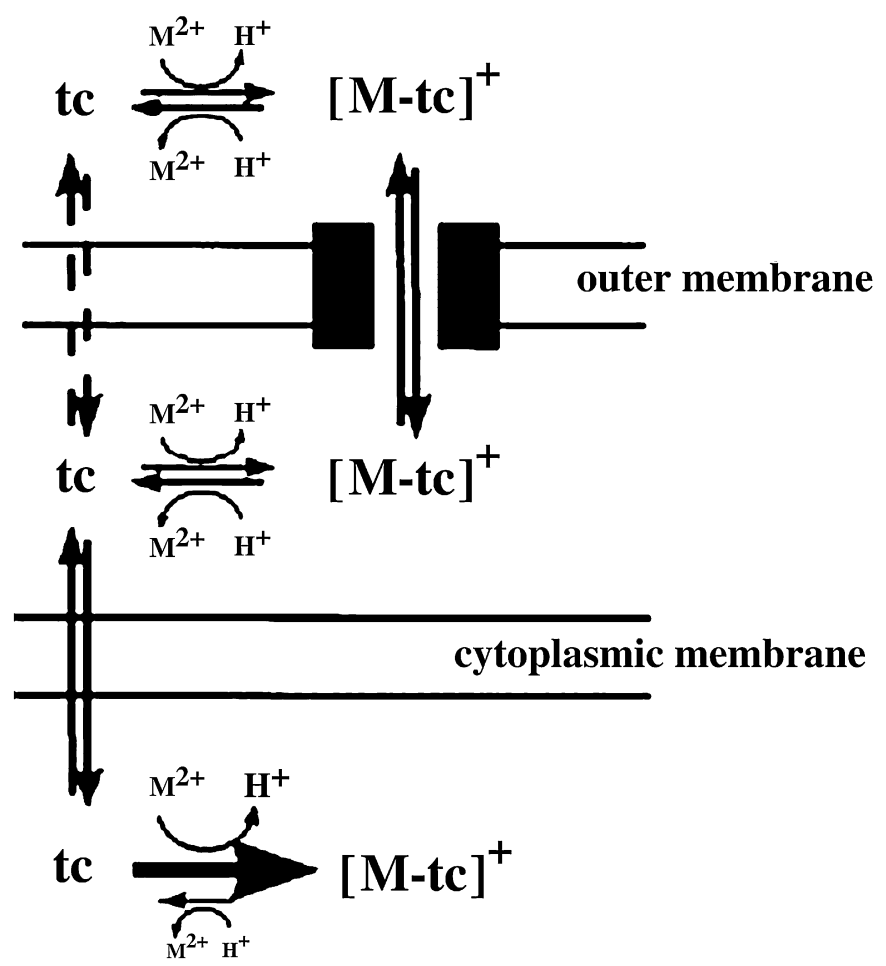

Fig. 1. Uptake of tetracycline by Escherichia coli as described in the text. Tetracycline, protons, metal cations, and the metal-tetracycline complex are depicted as tc, $\mathrm{H}^{+}, \mathrm{M}^{2+}$, and $[\mathrm{M}-\mathrm{tc}]^{+}$, respectively (Schnappinger and Hillen, 1996).
The results are likely to be important for other plants including vegetables that grow in soils contaminated with OTC.

\section{Materials and methods}

\subsection{Plant growth}

Alfalfa (Medicago sativa L.) seeds were surface sterilized with $10 \% \mathrm{H}_{2} \mathrm{O}_{2}$ for $10 \mathrm{~min}$, rinsed with distilled water and germinated in moist filter paper for $24 \mathrm{~h}$ and then sown in plastic containers filled with perlite for 1 week in a growth chamber. Two seedlings of uniform size were transplanted into a PVC pot $(7.5 \mathrm{~cm}$ in diameter, $14 \mathrm{~cm}$ in height $)$ containing $550 \mathrm{ml}$ of $1 / 3$-strength aerated nutrient solution for the first week and then shifted to the half-strength nutrient solution which had the following compositions of macronutrients (in $\mathrm{mM}$ ): $\mathrm{KNO}_{3}, 1.0 ; \mathrm{Ca}\left(\mathrm{NO}_{3}\right)_{2} \cdot 4 \mathrm{H}_{2} \mathrm{O}, 1.0 ; \mathrm{MgSO}_{4} \cdot 7 \mathrm{H}_{2} \mathrm{O}$, $0.4 ; \mathrm{KH}_{2} \mathrm{PO}_{4}, 0.3$; and of micronutrients (in $\mu \mathrm{M}$ ): ferric ethylenediaminetetraacetic acid (FeEDTA), 50; $\mathrm{ZnSO}_{4} \cdot 7 \mathrm{H}_{2} \mathrm{O}, \quad 1 ; \mathrm{CuSO}_{4} \cdot 5 \mathrm{H}_{2} \mathrm{O}, \quad 1$; $\mathrm{MnSO}_{4} \cdot \mathrm{H}_{2} \mathrm{O}, 5 ; \mathrm{H}_{3} \mathrm{BO}_{3}, 10 ; \mathrm{Na}_{2} \mathrm{MoO}_{4} \cdot \mathrm{H}_{2} \mathrm{O}, 0.5 ; \mathrm{CoSO}_{4} \cdot 7 \mathrm{H}_{2} \mathrm{O}, 0.2$. The initial $\mathrm{pH}$ of the solution was adjusted to 6.0 and the nutrient solution prepared with Millipore water (MilliQ, Billerica, MA, USA) was renewed every 3 days. Oxytetracycline was supplied as oxytetracycline hydrochloride (96\% purity, Sigma-Aldrich, Inc., USA). Plants were grown in a climate chamber under controlled conditions (photoperiod $16 \mathrm{~h}$ light $/ 8 \mathrm{~h}$ dark; temperature $25 / 21^{\circ} \mathrm{C}$ at day/night; relative humidity $60 \%$; light intensity $400 \mu \mathrm{mol} \mathrm{m}^{-2} \mathrm{~s}^{-1}$ ) for 3 weeks until mature roots $(20-25 \mathrm{~cm}$ in length) were developed.

\subsection{Experiment 1: Uptake and toxicity of OTC}

Uniform three-week-old seedlings of alfalfa were transferred to the nutrient solutions with OTC concentration of $0,0.0002,0.002,0.02,0.10$ and $0.20 \mathrm{mM}$ and were allowed to grow for 10 days under controlled conditions (see above). Plants were harvested, rinsed thoroughly with running water and distilled water, and blotted dry with tissue paper. Plants were then separated into shoots and roots, and fresh weights were recorded. There were four replicates per treatment.

\subsection{Experiment 2: Time-dependent uptake of OTC by alfalfa}

The roots were carefully excised at the basal node to ensure that the roots were exposed to open air for a minimal period, and were used in the following experiments. Excised alfalfa roots (about $2 \mathrm{~g}$ fresh weight; f.wt) were incubated in distilled water at room temperature for 20 min before assay (Chen et al., 2005). Each of the samples was then quickly blotted dry with tissue paper, placed in a conical flask $(200 \mathrm{ml})$ filled with $60 \mathrm{ml}$ half-strength nutrient solutions ( $\mathrm{pH}$ 6.0) containing 0.004 or $0.02 \mathrm{mM}$ OTC. The incubation was kept for $0.5,2,4$ and $8 \mathrm{~h}$ with continuous shaking. After the uptake period, ice-cold distilled water was used to wash the roots for $30 \mathrm{~min}$ to remove the surface-adsorbed OTC from alfalfa roots. The OTC concentrations in the equilibrium nutrient solutions and the washing distilled water were determined immediately by the HPLC method described below. Roots were then blotted dry with tissue paper and were immediately weighed. Sterility was maintained throughout the whole experiment. There were four replicates per treatment.

\subsection{Experiment 3: Kinetics of OTC uptake}

Batches of alfalfa roots (as above) were transferred to $200 \mathrm{ml}$ conical flasks containing $60 \mathrm{ml}$ half-strength nutrient solutions. The uptake of OTC was determined in the solutions with OTC at concentrations of $0,0.0020$, $0.0040,0.008,0.016,0.032$ and $0.064 \mathrm{mM}$. Other procedures were the same as described above. 


\subsection{Experiment 4: OTC uptake by alfalfa roots influenced by $\mathrm{pH}$}

The $\mathrm{pH}$ value of the test solutions was buffered using 2-( $N$-morpholino) ethanesulfonic acid (MES) or 3-( $N$-morpholino) propanesulfonic acid (MOPS). Excised alfalfa roots were shaken for $1 \mathrm{~h}$ in the test solutions, half-strength nutrient solution with $0.02 \mathrm{mM}$ OTC plus $5 \mathrm{mM}$ MES (pH 5.4-6.7) or $5 \mathrm{mM}$ MOPS ( $\mathrm{pH} 6.5-7.9)$. Other procedures were the same as described above.

\subsection{Experiment 5: OTC uptake influenced by metabolic and aquaporin inhibitors}

OTC uptake was investigated using the procedure described elsewhere (Meharg and Jardine, 2003; Liang et al., 2005). The metabolic inhibitor, 2,4-DNP, was added at a concentration of $1 \mathrm{mM}$ to suppress the uptake of OTC. For the treatments with aquaporin inhibitors, either $\mathrm{HgCl}_{2}(0.01$ and $\left.0.1 \mathrm{mM} \mathrm{Hg}^{2+}\right)$ or $\mathrm{AgNO}_{3}\left(0.5\right.$ and $\left.5 \mu \mathrm{M} \mathrm{Ag}^{+}\right)$or glycerol $(1$ and $10 \mathrm{mM})$ was used. Test solutions had $0.02 \mathrm{mM}$ OTC or a range of concentration of inhibitors plus $0.02 \mathrm{mM}$ OTC. The 3 -week-old alfalfa roots were transferred to the test solutions and shaken for $1 \mathrm{~h}$. The OTC concentrations in the equilibrium test solutions and the washing distilled water were determined immediately. There were four replicates per treatment.

\subsection{Experiment 6: OTC uptake by excised roots influenced by 2,4-DNP at two $\mathrm{pH}$ values}

Initial observation showed that the addition of 2,4-DNP decreased the $\mathrm{pH}$ value of nutrient solution. In order to exclude the possible inhibitory effects of $\mathrm{pH}$, we characterized OTC uptake by alfalfa roots and by alfalfa plants as influenced by 2,4-DNP at two $\mathrm{pH}$ values. There were four treatments with four replicates each: i.e. Control (nutrient solution $\mathrm{pH}$ 6.0), MES (pH 6.0), 2,4-DNP (pH 3.5), and 2,4-DNP plus MES (pH 6.0). All test solutions contained $0.02 \mathrm{mM}$ OTC. Excised alfalfa roots were excised and placed in a $200 \mathrm{ml}$ conical flask containing $60 \mathrm{ml}$ test solutions described above. Other procedures were the same as described above.

\subsection{Experiment 7: OTC uptake by intact plants influenced by 2,4-DNP at two $\mathrm{pH}$ values}

The experiment consisted of four treatments with four replicates: i.e. control (nutrient solution, $\mathrm{pH}$ 6.0), $0.02 \mathrm{mM}$ OTC, $0.02 \mathrm{mM}$ OTC plus $1 \mathrm{mM} \mathrm{2,4-}$ DNP (pH 3.5) and $0.02 \mathrm{mM}$ OTC plus $1 \mathrm{mM}$ 2,4-DNP (pH 6.0).

Uniform 3-week-old seedlings were transferred to distilled water for $30 \mathrm{~min}$ and blotted dry with tissue paper. Two plants were transferred to an aluminum-foil wrapped brown flask containing $300 \mathrm{ml}$ test solutions described above after the light period had already started for $2 \mathrm{~h}$. After $24 \mathrm{~h}$, the concentration of OTC in the uptake solution was determined by HPLC and the water loss from transpiration was also recorded by weighing.

\subsection{Determination of OTC by the HPLC method}

Acetonitrile and methanol were of HPLC grade, and ammonium acetate, formic acid, sodium hydroxide were of analytical reagent grade. Water was prepared in-house by a Milli-Q system (Millipore, Eschborn, Germany). Stock solutions of OTC standard prepared by dissolving $1 \mathrm{mg}$ of OTC in $1 \mathrm{ml}$ of methanol were stored at $-80^{\circ} \mathrm{C}$ and were stable for at least 2 months. Working solutions were prepared freshly for the assay of OTC.

OTC was determined following the method of Hamscher et al. (2002). The concentration in equilibrium solution was measured by the reversed-phase HPLC method. The HPLC system was a gradient system consisting of a Waters 515 pump, a Waters 2996 photodiode array detector acquiring spectra at $355 \mathrm{~nm}$ with a resolution of $1.2 \mathrm{~nm}$ and a data acquisition rate of 1 spectrum $/ 4 \mathrm{~s}$ and a Sunfire C18 column $(5 \mu \mathrm{m}, 4.6 \times 150 \mathrm{~mm}$, Waters Corp., USA) operated at $25{ }^{\circ} \mathrm{C}$. The mobile phase consisted of $0.5 \%$ formic acid in water with $1 \mathrm{mM}$ ammonium acetate (solvent $\mathrm{A}, \mathrm{pH} 2.5$ ), and acetonitrile (solvent B). The flow was of $1 \mathrm{ml} / \mathrm{min}$. The gradient run was $0-50 \%$ B in $9 \mathrm{~min}$ and then held at $50 \%$ B for $1 \mathrm{~min}$. After each run, the column was rinsed for 3 min with $99 \%$ acetonitrile and re-equilibrated for $12 \mathrm{~min}$ with solvent $\mathrm{A}$. The injection volume was $20 \mu \mathrm{l}$.

Calibration curves constructed for OTC ranged from 0.001 to $40 \mathrm{mM}$ for OTC concentration-dependent experiment with $r^{2}=0.9999$ and from 0.002 to 0.040 for other experiments with $r^{2}=0.9995$. Qualification was obtained by comparing the peak areas of the sample, which was assessed using the Milleuiumatography manager V2.10 software, with that of the external calibration curves.

\subsection{Statistical analysis}

Analysis of variance on plant shoot and root biomass and concentrations of OTC was performed with SPSS 11.0 (SPSS Inc., Chicago, MI, USA).

\section{Results}

\subsection{Uptake and toxicity of OTC}

Both shoot and root biomass of alfalfa decreased sharply with increasing concentrations of OTC in the growth solution (Fig. 2). OTC had no effect on alfalfa shoot biomass at OTC concentration of $0.002 \mathrm{mM}$, but decreased the root biomass significantly $(p<0.05)$ when the OTC concentration was

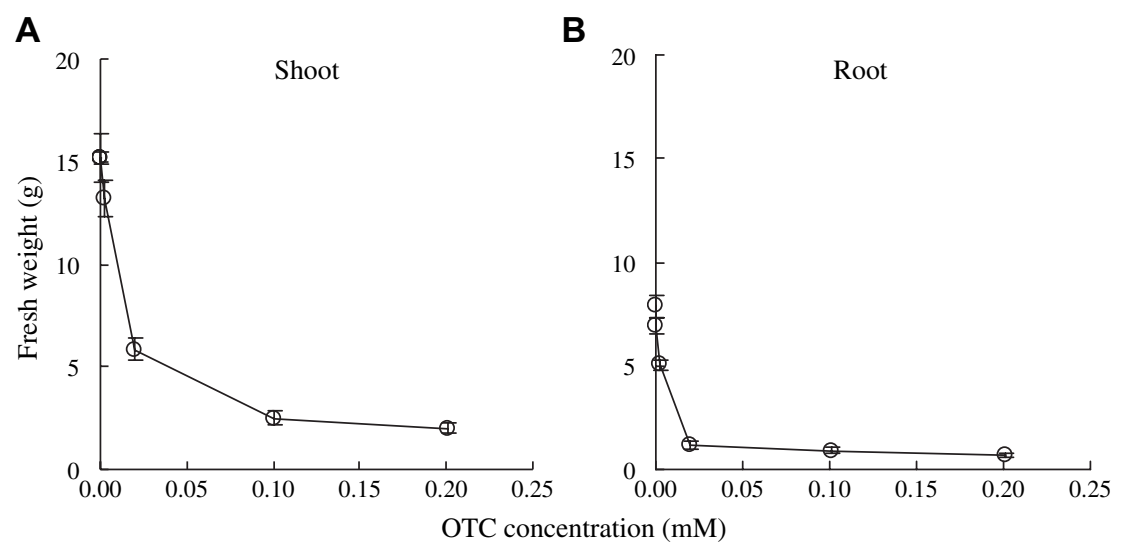

Fig. 2. Effects of oxytetracycline on (A) shoot and (B) root fresh weights in Experiment 1. Each point is the average of four replicates, and bars represent \pm SE of the mean. 
above $0.002 \mathrm{mM}$. In addition, the ratio of shoot/root increased significantly at lower OTC concentrations, suggesting that the roots are more sensitive to OTC than shoots. OTC decreased shoot and root fresh weight by a maximum of $61 \%$ and $85 \%$, respectively (Fig. 2). The leaves became weakly green at $0.02 \mathrm{mM}$, and the shoots wilted at higher concentrations $(0.10$ and $0.20 \mathrm{mM})$.

\subsection{Time-dependent and kinetics of OTC uptake}

The results of time-dependent uptake of OTC at external concentrations of 0.004 and $0.02 \mathrm{mM}$ (Experiment 2) showed that the net uptake increased linearly within $4 \mathrm{~h}$, after which OTC uptake started to slow down (Fig. 3). Kinetics of OTC uptake (Experiment 3 ) by alfalfa roots was adequately described by the Michaelis-Menten function (Fig. 4, $p<0.0001$ ). The calculated $V_{\max }$ was $2.25 \mu \mathrm{mol} \mathrm{g}^{-1}$ f.wt h ${ }^{-1}$, and $K_{\mathrm{m}}$ was $0.036 \mathrm{mM}$.

\subsection{OTC uptake influenced by $\mathrm{pH}$, metabolic and aquaporin inhibitors}

OTC uptake was the lowest at $\mathrm{pH} 5.0$, and the highest at $\mathrm{pH}$ 7.0 (Fig. 5). Treatment with $1 \mathrm{mM}$ 2,4-DNP decreased OTC uptake by alfalfa roots by $74.8 \%$ (Table 1 ). OTC uptake at external concentration of $0.02 \mathrm{mM}$ was decreased by 42.4 and $46.1 \%$ when the plants were treated with 0.01 and $0.1 \mathrm{mM}$ $\mathrm{Hg}^{2+}$ (Table 1). Silver had no effect on OTC uptake by alfalfa roots at 0.5 or $5 \mathrm{mM}$. Glycerol at either 1 or $10 \mathrm{mM}$ had no effects on OTC uptake (Table 1).

\subsection{Inhibitory effects of 2,4-DNP on OTC uptake at two pH values}

The uptake of OTC by alfalfa roots was inhibited significantly by 2,4-DNP at two $\mathrm{pH}$ values $(\mathrm{pH} 6.0$ and 3.5) (Fig. 6). Furthermore, OTC uptake by intact alfalfa plants was also inhibited notably by 2,4-DNP at $\mathrm{pH} 3.5$ within a 24-h period, although low $\mathrm{pH}$ value (3.5) reduced OTC uptake by alfalfa plants compared with the control ( $\mathrm{pH}$ 6.0)

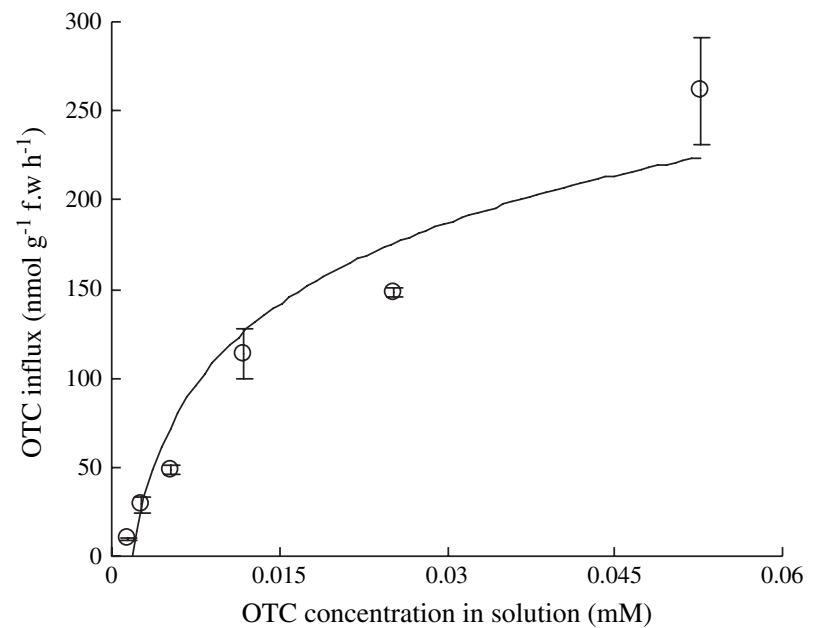

Fig. 4. Concentration-dependent kinetics of OTC uptake by alfalfa (Medicago sativa) roots in Experiment 3. Each point is the average of four replicates and bars represent $\pm \mathrm{SE}$ of the mean.

(Fig. 7). Fig. 7 also shows that OTC had no effect on transpirational water loss compared with the control, but 2,4-DNP significantly inhibited transpiration.

\section{Discussion}

OTC had significant inhibitory effect on alfalfa growth at concentrations higher than $0.02 \mathrm{mM}$. Root growth was more sensitive to OTC than shoot, which is in agreement with the findings of Migliore et al. (2003), who showed that plant roots are the main sites of antimicrobial drug accumulation. Alfalfa leaves turned light green or even yellow with increasing OTC doses. The phytotoxicity might be caused by the inhibition of translational activity of chloroplast and chloroplast (p)ppGpp synthase activity by tetracycline, which is structurally similar to OTC (Bradel et al., 2000; Kasai et al., 2004).

Dissolved species of OTC may have net positive charges $(\mathrm{pH}<3.6)$, neutral $(3.6<\mathrm{pH}<7.5)$ and negative $(\mathrm{pH}>7.5)$ (Fig. 8) because OTC is a weak polyprotic acid. Our data showed that OTC uptake by alfalfa was $\mathrm{pH}$-dependent with

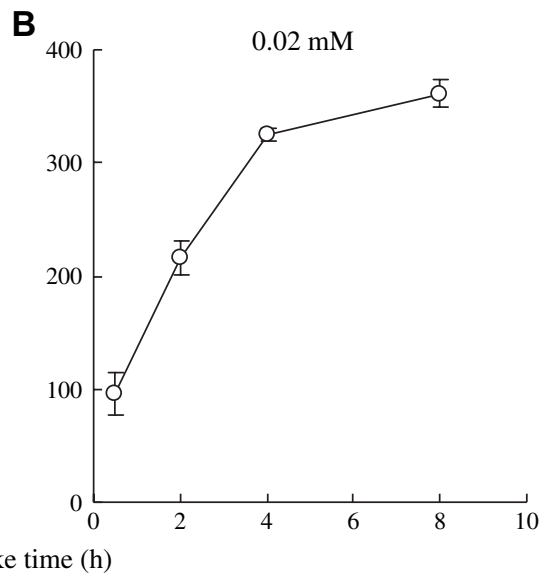

Fig. 3. Time-dependent uptake of OTC at external concentrations of (A) $0.004 \mathrm{mM}$ and (B) $0.02 \mathrm{mM}$ by alfalfa (Medicago sativa) roots in Experiment 2. Each point is the average of four replicates and bars represent $\pm \mathrm{SE}$ of the mean. 


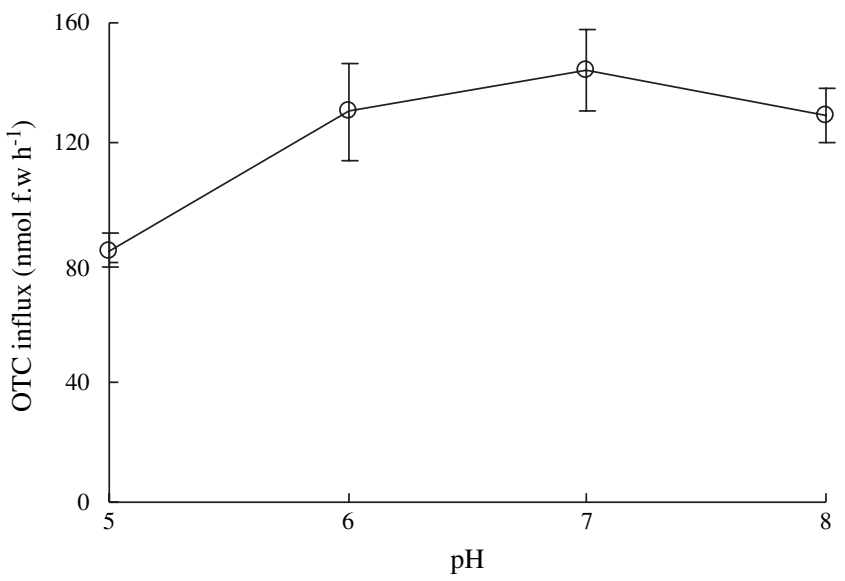

Fig. 5. Effects of solution $\mathrm{pH}$ on OTC uptake by alfalfa roots in Experiment 4. Each point is the average of four replicates and bars represent \pm SE of the mean.

the lowest uptake at $\mathrm{pH}$ 5.0, suggesting that OTC molecules could be easily taken up by alfalfa roots at higher $\mathrm{pH}$. This pH-dependent uptake of OTC was observed not only by alfalfa roots but also by intact alfalfa plants (Fig. 7). Thus, soil solution $\mathrm{pH}$ is an important factor influencing the bioavailability of OTC in soil (Kulshrestha et al., 2004; Figueroa and Mackay, 2005; Figueroa et al., 2005; Gu, 2005; Jones et al., 2005) and the transport from soil to plant.

Time-dependent uptake of OTC by alfalfa showed that there was an equilibrium status of OTC uptake after $4 \mathrm{~h}$ (Fig. 3). Thus, follow-up short-term uptake experiments were performed within one hour, because OTC uptake within the 4-h-uptake period increased linearly $\left(r^{2}=0.994\right.$ for $0.004 \mathrm{mM}$ and 0.999 for $0.02 \mathrm{mM}$ ) with time. The kinetics of OTC uptake into alfalfa roots was well fitted to the Michaelis-Menten equation. Further experiments in the present study showed that OTC uptake by alfalfa roots and plants was inhibited significantly by the metabolic inhibitor 2,4-DNP. It is well documented that 2,4-dinitrophenol (2,4-DNP) is regarded as an uncoupler of oxidative (and to a lesser extent, photosynthetic), phosphorylation, and of proton-coupled fluxes at the plasma membrane and endomembrane via the dissipation of trans-membrane electrochemical gradients of protons (Liang et al., 2005). The significant inhibition of OTC uptake by the uncoupler DNP and the good description of OTC uptake by Michaelis-Menten model (Figs. 4-7 and Table 1), suggested that the transport of OTC into alfalfa roots was an energy-dependent process, which requires selective binding sites.

To investigate whether OTC uptake by plant could be facilitated by water channels, we used $\mathrm{Hg}^{2+}, \mathrm{Ag}^{+}$and glycerol e to inhibit or compete for the aquaporins in alfalfa roots. Aquaporins are sensitive to $\mathrm{Hg}^{2+}$, which inhibits water via covalent

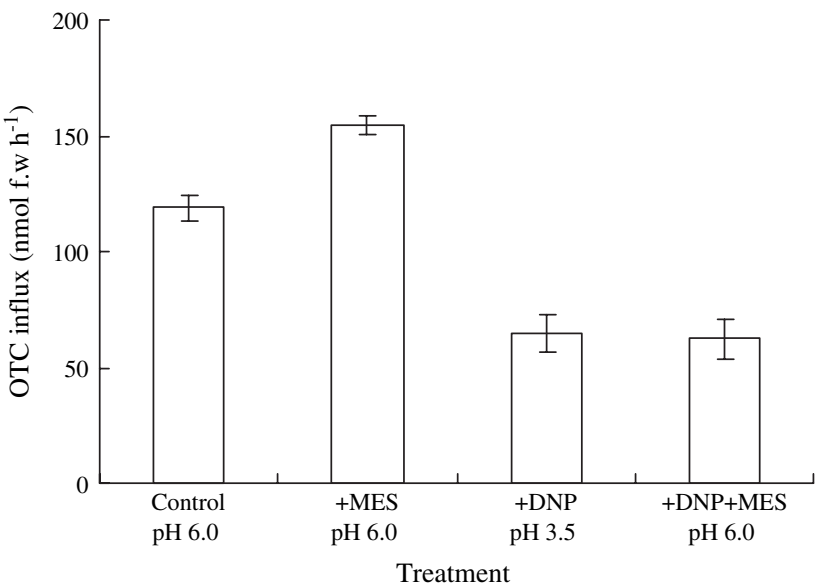

Fig. 6. Effects of 2,4-DNP at pH 3.5 and 6.0 on OTC uptake in Experiment 6. Bars represent $\pm \mathrm{SE}$ of the mean.

modification of crysteine residues within the water pore and in other regions of the protein causing either blockage or conformational changes leading to the inhibition of water transport (Barone et al., 1998). OTC uptake by alfalfa roots was decreased when exposed to 0.01 and $0.1 \mathrm{mM} \mathrm{Hg}^{2+}$ compared with the control (Table 1). However, the reduction in OTC uptake after the addition of $\mathrm{Hg}^{2+}$ could be due to general disruption of plasma membrane biochemistry caused by the highly toxic $\mathrm{Hg}^{2+}$ ion (Dordas and Brown, 2001; Martre et al., 2001; Du et al., 2005), rather than specific inhibition of aquaporins (Meharg and Jardine, 2003). To further elucidate the possible role of aquaporins in OTC uptake, we used the other competitors, such as glycerol and $\mathrm{Ag}^{+}$. Glycerol is widely used to assay aquaporins activity (Biela et al., 1999), and has a low phytotoxicity. Silver is another more potent inhibitor of aquaporins than the commonly used mercury (Niemietz and Tyerman, 2002). It is likely that silver reacts with the sulfhydryl group of a cysteine in the vicinity of the conserved NPA motif and thus effectively blocks the constriction region of the water channel. Our findings showed that glycerol and $\mathrm{Ag}^{+}$did not compete with OTC for uptake and transport into alfalfa roots, suggesting that OTC does not enter into the root through water channels. The glycerol concentration of $10 \mu \mathrm{M}$ used in the present study was high enough to inhibit arsenite uptake by rice within $20 \mathrm{~min}$, which is sufficient for the inhibition of aquaporins (Meharg and Jardine, 2003), and the $5 \mu \mathrm{M}$ of $\mathrm{Ag}^{+}$ was also suitable (Niemietz and Tyerman, 2002). Therefore, our data convincingly demonstrated that OTC uptake was aquaporins-independent.

The adverse effects observed on alfalfa and other plants have important implications in agricultural systems where livestock

Table 1

OTC uptake as influenced by metabolic inhibitors (2,4-DNP) and aquaporin inhibitors $\left(\mathrm{Hg}^{2+}, \mathrm{Ag}^{+}\right.$and glycerol)

\begin{tabular}{|c|c|c|c|c|c|c|c|c|}
\hline & Control & 2,4-DNP (mM) & $\mathrm{Hg}^{2+}(\mathrm{mM})$ & & $\mathrm{Ag}^{+}(\mu \mathrm{M})$ & & Glycerol (mM) & \\
\hline Concentration & & 0.001 & 0.01 & 0.1 & 0.5 & 5 & 1 & 10 \\
\hline OTC influx $\left(\mathrm{nmol}^{-1}\right.$ f.wt $\left.\mathrm{h}^{-1}\right)$ & $138.7 \pm 3.9$ & $35.0 \pm 2.1$ & $79.9 \pm 4.1$ & $74.7 \pm 8.8$ & $129.8 \pm 9.7$ & $158.1 \pm 13.9$ & $159.9 \pm 12.9$ & $161.8 \pm 14.7$ \\
\hline
\end{tabular}

Data are expressed as mean $\pm \mathrm{SE}$. 

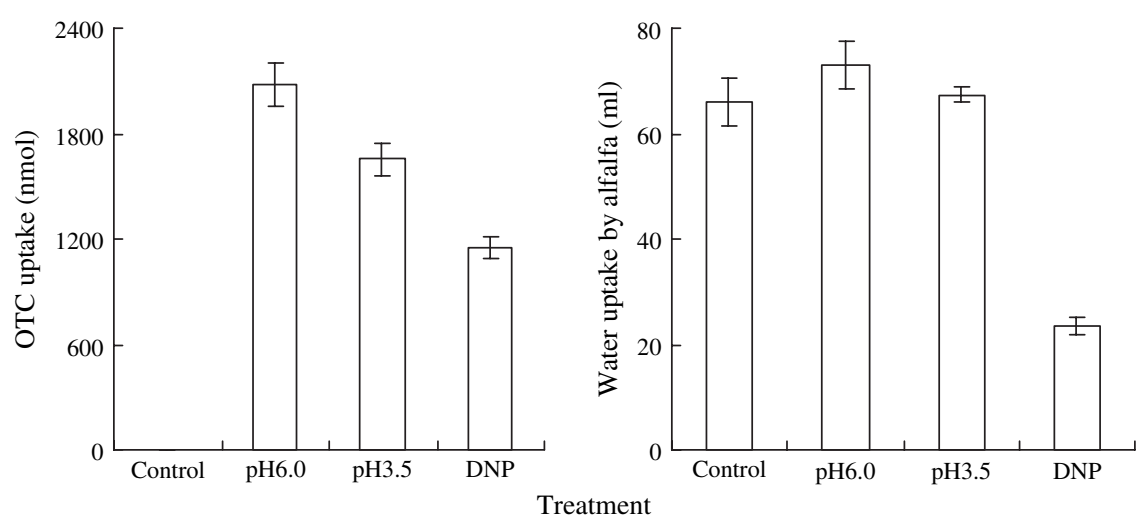

Fig. 7. OTC and water uptake by intact alfalfa plants grown with OTC at concentration of $0.02 \mathrm{mM}$ for $24 \mathrm{~h}$ in Experiment 7 . Bars represent \pm SE of the mean.

manure, wastewater or treated sewage sludge which might contain some of the commonly used antibiotic agents are applied to agricultural fields (Kümmerer, 2001). Therapeutic agents might convey antibiotics from the soil into the food chain of human beings due to the uptake and bioaccumulation of these agents by plants grown in the antibiotic-contaminated soils.

In conclusion, antibiotics are potentially phytotoxic to and are accumulated by higher plants, including vegetables and crops. Results from the present study demonstrate that plant uptake of OTC is energy dependent, and aquaporins in root cell membranes may not contribute to the uptake of OTC. The accumulation of antibiotics such as OTC in plants may pose health risks to animals and humans. Therefore, further research activities should focus on investigating the mechanism for uptake of other veterinary antibiotics into plant roots, their root to shoot translocation, and their accumulation in plants, especially in vegetables.
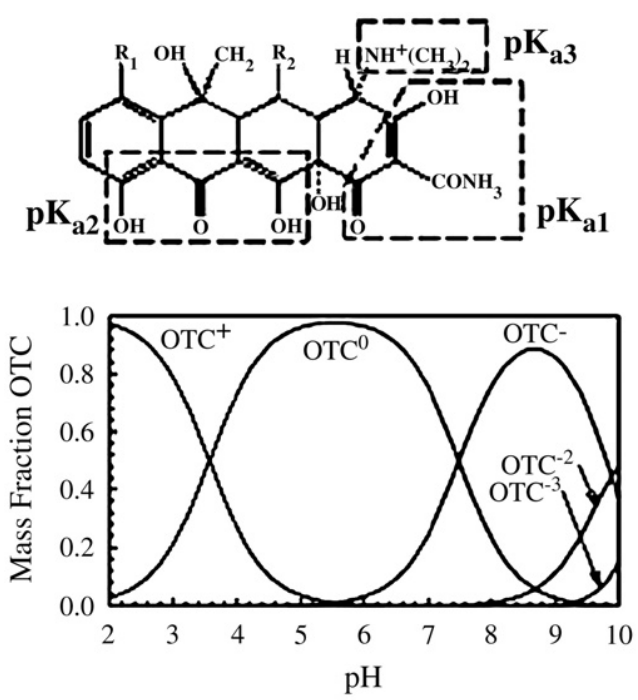

\begin{tabular}{|c|c|c|c|}
\hline Antibiotic & $\mathrm{pKal}$ & $\mathrm{pKa} 2$ & $\mathrm{pKa} 3$ \\
\hline OTC & 3.57 & 7.49 & 9.88 \\
\hline
\end{tabular}

Fig. 8. OTC chemistry and solution speciation shown with environmentally relevant $\mathrm{pH}$ value (Tavares and McGuffin, 1994).

\section{Acknowledgments}

This study was financially supported by the Chinese Academy of Sciences (KZCX3-SW-431) and the Natural Science Foundation of China (40321101).

\section{References}

Barone, L.M., He, M., Helen, S., Connie, J., Kashlan, K.B., Wasserman, B.P., 1998. Distinct biochemical and topological properties of the $31-$ and $27-$ kilodalton plasma membrane intrinsic protein subgroups from red beet. Plant Physiology 118, 315-322.

Batchelder, A.R., 1981. Chlorotetracycline and oxytetracycline effects on plant growth and development in liquid culture. Journal of Environmental Quality 10, 515-518.

Batchelder, A.R., 1982. Chlorotetracycline and oxytetracycline effects on plant growth and development in soil systems. Journal of Environmental Quality 11, 675-678.

Biela, A., Grote, K., Otto, B., Hoth, S., Hedrich, R., Kaldenjoff, R., 1999. The Nicotiana tabacum membrane aquaporin NtAQP1 is mercury-insensitive and permeable for glycerol. Plant Journal 18, 565-570.

Boxall, A.B.A., Koipin, D.W., Tolls, J., 2003. Are veterinary medicines causing environmental risks? Environmental Science and Technology 37, 265A-304A.

Bradel, B.G., Preil, W., Jeske, H., 2000. Remission of the free-branching pattern of Euphorbia pulcherrima by tetracycline treatment. Journal of Phytopathology 148, 587-590.

Chen, Z., Zhu, Y.G., Liu, J.W., Meharg, A.A., 2005. Direct evidence showing the effect of root surface iron plaque on arsenite and arsenate uptake into rice (Oryza sativa) roots. New Phytologist 31, 91-97.

Chopra, I., Roberts, M., 2001. Tetracycline antibiotics: mode of action, applications, molecular biology, and epidemiology of bacterial resistance. Microbiology and Molecular Biology Reviews 65, 232-260.

Dordas, V., Brown, P.H., 2001. Evidence for channel mediated transport of boric acid in squash (Cucurbita pepo). Plant and Soil 235, 95-103.

Du, X., Zhu, Y.G., Liu, W.J., Zhao, X.S., 2005. Uptake of mercury (Hg) by seedlings of rice (Oryza sativa L.) grown in solution culture and interactions with arsenate uptake. Environmental Experimental Botany 54, 1-7.

Figueroa, R., Mackay, A., 2005. Sorption of oxytetracycline to iron oxides and iron oxide-rich soils. Environmental Science and Technology 39, 6664-6671.

Figueroa, R., Leonard, A., Mackay, A., 2005. Modeling tetracycline antibiotic sorption to clays. Environmental Science and Technology 38, 476-483.

$\mathrm{Gu}, \mathrm{C} ., 2005$. Interaction of tetracycline with aluminum and iron hydrous oxides. Environmental Science and Technology 39, 2660-2667.

Halling-Sørensen, B., Jørgensen, S.E., 2000. Drugs in the environment. Chemosphere 40, 691-699. 
Hamscher, G., Sczesny, S., Höper, H., Nau, H., 2002. Determination of persistent tetracycline residues in soil fertilized with liquid manure by high-performance liquid chromatography with electrospray ionization tandem mass spectrometry. Analytical Chemistry 74, 1509-1518.

Jjemba, P.K., 2002a. The potential impact of veterinary and human therapeutic agents in manure and biosolids on plants grown on arable land: a review. Agriculture, Ecosystems and Environment 93, 267-278.

Jjemba, P.K., 2002b. The effect of chloroquine, quinacrine, and metronidazole on both soybean plants and soil microbiota. Chemosphere 46, 1019-1025.

Jones, A.D., Bruland, G.L., Agrawal, S.G., Vasudevan, D., 2005. Factors influencing the sorption of oxytetracycline to soils. Environmental Toxicology Chemistry 24, 761-770.

Jørgensen, S.E., Halling-Sørensen, B., 2000. Drugs in the environment. Chemosphere 40, 691-699.

Kasai, K., Kanno, T., Endo, Y., Wakasa, K., Tozawa, Y., 2004. Guanosine tetra- and pentaphosphate synthase activity in chloroplasts of a higher plant: association with $70 \mathrm{~S}$ ribosomes and inhibition by tetracycline. Nucleic Acids Research 32, 5732-5741.

Kolpin, D.W., Furlong, E.T., Meyer, M.T., Thurman, E.M., Zaugg, S.D., Barber, L., Buxton, H.T., 2002. Pharmaceuticals, hormones, and other organic wastewater contaminants in U.S. streams, 1999-2000, a national reconnaissance. Environmental Science and Technology 36, 1202-1211.

Kulshrestha, P., Giese, R.F., Aga, R.S., 2004. Investigating the molecular interactions of oxytetracycline in clay and organic matter: insights on factors affecting its mobility in soil. Environmental Science and Technology 38, 4097-4105

Kümmerer, K., 2001. Drugs in the environment: emission of drugs, diagnostic aids and disinfectants into wastewater by hospitals in relation to other sources - review. Chemosphere 47, 957-969.

Liang, Y.C., Si, J., Römheld, V., 2005. Silicon uptake and transport is an active process in Cucumis sativus L. New Phytologist 167, 797-804.
Loke, M.L., Tjørnelund, J., Halling-Sørensen, B., 2002. Determination of the distribution coefficient ( $\log \mathrm{Kd}$ ) of oxytetracycline, tylosin, A., olaquindox and metronidazole in manure. Chemosphere 48, 351-361.

Martre, P., North, G.B., Nobel, P.S., 2001. Hydraulic conductance and mercury-sensitive water transport for roots of Opuntia acanthocarpa in relation to soil drying and rewetting. Plant Physiology 126, 352-362.

Meharg, A.A., Jardine, L., 2003. Arsenite transport into paddy rice (Oryza sativa) roots. New Phytologist 157, 39-44.

Migliore, L., Civitareale, C., Cozzolino, S., Casoria, P., Brambilla, G., Gaudio, L., 1998. Laboratory models to evaluate phytotoxicity of sulphadimethoxine on terrestrial plants. Chemosphere 37, 2957-2961.

Migliore, L., Cozzolino, S., Fiori, M., 2003. Phytotoxicity to and uptake of enrofloxacin in crop plants. Chemosphere 40, 741-750.

Niemietz, C.M., Tyerman, S.D., 2002. New potent inhibitors of aquaporins: silver and gold compounds inhibit aquaporins of plant and human origin. FEBS Letters 531, 443-447.

Nikaido, H., Thanassi, D.G., 1993. Penetration of lipophilic agents with multiple protonation sites into bacterial cells: tetracyclines and fluoroquinolones as examples. Antimicrobial Agents Chemotherapy 37, 1393-1399.

Schnappinger, D., Hillen, W., 1996. Tetracyclines: antibiotic action, uptake, and resistance mechanisms. Archives of Microbiology 165, 359-369.

Simon, N.S., 2005. Loosely bound oxytetracycline in riverine sediments from two tributaries of the Chesapeake Bay. Environmental Science and Technology 39, 3480-3487.

Tavares, M.F.M., McGuffin, V.L., 1994. Separation and characterization of tetracycline antibiotics by capillary electrophoresis. Journal of Chromatography A $686,129-142$.

Thiele-Bruhn, S., 2003. Pharmaceutical antibiotic compounds in soils-a review. Journal of Plant Nutrition and Soil Science 166, 145-167.

Tolls, J., 2001. Sorption of veterinary pharmaceuticals in soils: A review. Environmental Science and Technology 35, 3397-3406. 